\title{
Extending Postpartum Coverage for Medicaid Moms
}

Michelle Winokur, DrPH, and the AfPA Governmental Affairs

Team, Alliance for Patient Access (AfPA)

The Alliance for Patient Access (allianceforpatientaccess.org), founded in 2006, is a national network of physicians dedicated to ensuring patient access to approved therapies and appropritraining and mobilizing policy-minded physicians to be effective advocates for patient access. AfPA is organized as a non-profit 501(c)(4) corporation and headed by an independent board of directors. Its physician leadership is supported by policy advocacy management and public affairs consultants. In 2012, AfPA established the Institute for Patient Access (IfPA), a related 501(c) (3) non-profit corporation. In keeping with its mission to promote a better understanding of the benefits of the physician-patient relationship in the provision of quality healthcare, IfPA sponsors policy research and educational programming.

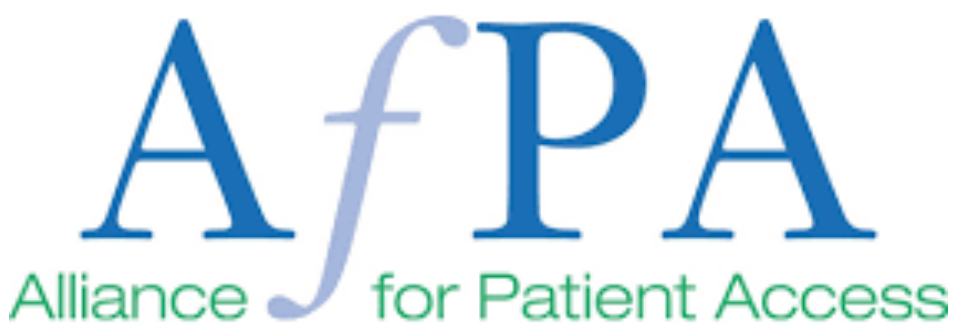
ate clinical care. AfPA accomplishes this mission by recruiting,

\section{Extending Postpartum Coverage}

A provision in the COVID-19 rescue package, passed in March, gives states the option to extend postpartum coverage to 12 months after birth starting in April 2022. (1) If every state opted in, insurance would be extended for approximately 2 million moms. Moreover, it is not for just pregnancy-related care. States that chose to extend coverage are required to provide full Medicaid benefits.

Extended Medicaid coverage will likely reduce "churn" for new moms when they move between insured and uninsured. Data show that approximately one-third of women experience a coverage disruption between conception and postpartum. As expected, that can mean gaps in care, increased emergency department use, and worse health outcomes.

\section{States Take Action}

As of June 24,19 states had already taken some action to extend their coverage. (2)

Offering extended coverage after the end of the public health emergency but before April 1, 2022, will require states to use only state funds to pay for the care or obtain permission in the form of an 1115 waiver.

Three states - Missouri, Illinois, and Georgia - already had their waiver requests approved. Georgia's extension is for six months; the others are for 12. Massachusetts, New Jersey, and Maryland have requests pending with the federal government.

California has taken the biggest steps toward expanding coverage. Last year, policymakers authorized the use of state funds to provide up to 12 months of postpartum Medicaid coverage for moms who have a maternal mental health condition, such as postpartum depression. The policy has been in place since August 2020; the state legislature is currently considering a bill that would more broadly extend coverage.

\section{About Medicaid Coverage}

Medicaid insures nearly half of all babies born in the United States. That is, in part, because uninsured low-income women become eligible for Medicaid when they become pregnant.

\section{"Medicaid insures nearly half of all babies born in the United States. That is, in part, because uninsured low-income women become eligible for Medicaid when they become pregnant."}

Expectant mothers and their unborn infants are monitored, measured, and closely watched for almost a year before birth. However, nearly half of new moms are at risk of losing their health insurance just two months after their baby arrives.

For Medicaid, 60 days is the minimum coverage period required by law. After that, some women, especially those who live in states that did not expand Medicaid under the Affordable Care Act, do not have a clear path to continued coverage.

But it looks like that may be changing.
As a jointly funded state and federal program, Medicaid minimum coverage and eligibility requirements are established by the Centers for Medicare and Medicaid Services. States must cover pregnant women with incomes up to $138 \%$ of the federal poverty level, about $\$ 17,700$. Many choose to cover those with higher incomes. Some provide coverage for women who make up to $380 \%$ of the federal poverty level, or around $\$ 48,000$. 


\section{Prioritizing Maternal Health}

Creating the opportunity for states to expand postpartum Medicaid coverage is just one of the Biden administration's initiatives to improve maternal and infant health. This approach aims to address preventable maternal mortality and morbidity, which are worse in the United States than in other high-income countries.

Reducing churn through extended coverage should benefit moms from communities of color, who disproportionally experience loss of insurance coverage and worse maternal health outcomes, including preventable death. Black women in the United States are 2-3 times more likely to die from a pregnancy-related complication than non-Hispanic white women.

The federal government has opened the door to change the health course for new moms across the country. Now, it is up to policymakers in each state to make the opportunity possible for its residents.

\section{References:}

1. https://www.congress.gov/bill/117th-congress/ house-bill/1319/text\#toc-HD0A062309C1143928EF82EC5845217C3/

2. https://www.healthaffairs.org/do/10.1377/ hblog20190913.387157/full/

3. https://www.kff.org/medicaid/issue-brief/medicaid-postpartum-coverage-extension-tracker/

Disclosures: Michelle Winokur, DrPH, is the Policy Communications Director for the Alliance for Patient Access.

\section{NT}
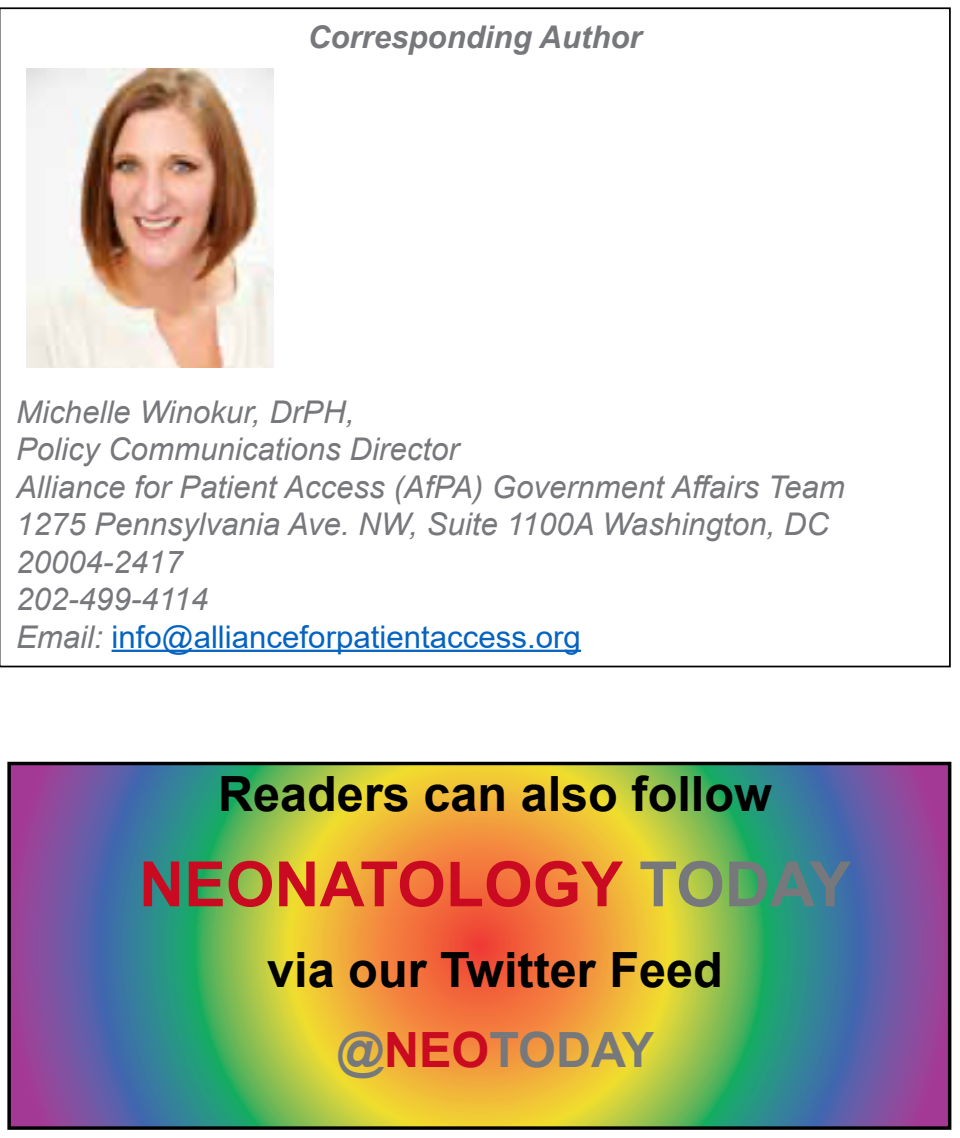
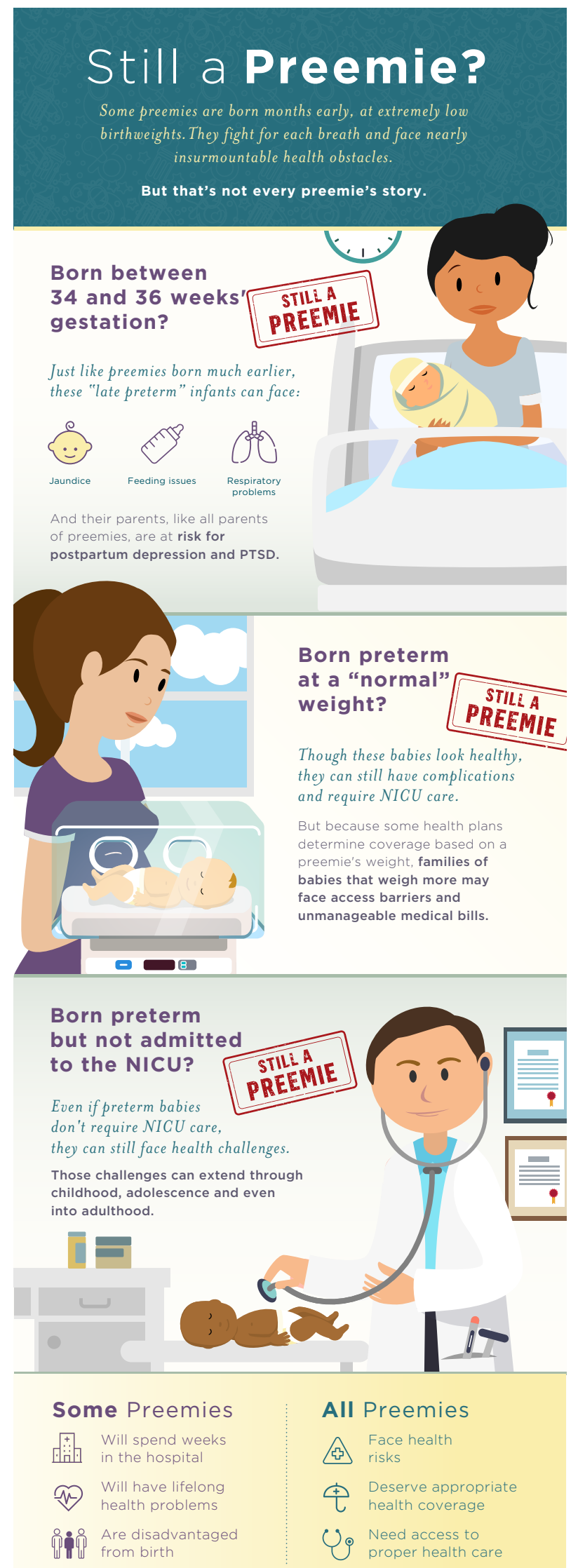

All Preemies

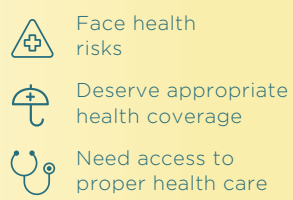

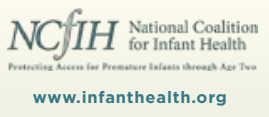

